\title{
A Community-dwelling Older Adult with Concurrent Human Immunodeficiency Virus, Type 1 Diabetes Mellitus and Peripheral Neuropathy: A Case Report.
}

Kevin Kohl

University of Colorado Anschutz Medical Campus, Aurora, CO, Kevin.Kohl@ucdenver.edu

Tara Ferguson

St. Anthony's Hospital, Lakewood, CO, TaraFerguson@centura.org

Shane O'Malley

somalley27@gmail.com

Tamara S. Struessel

University of Colorado Anschutz Medical Campus, Aurora, CO, tami.struessel@ucdenver.edu

Follow this and additional works at: https://nsuworks.nova.edu/ijahsp

Part of the Medicine and Health Sciences Commons

\section{Recommended Citation}

Kohl K, Ferguson T, O'Malley S, Struessel TS. A Community-dwelling Older Adult with Concurrent Human Immunodeficiency Virus, Type 1 Diabetes Mellitus and Peripheral Neuropathy: A Case Report.. The Internet Journal of Allied Health Sciences and Practice. 2019 Jan 01;17(2), Article 14.

This Case Study is brought to you for free and open access by the College of Health Care Sciences at NSUWorks. It has been accepted for inclusion in Internet Journal of Allied Health Sciences and Practice by an authorized editor of NSUWorks. For more information, please contact nsuworks@nova.edu. 


\title{
A Community-dwelling Older Adult with Concurrent Human Immunodeficiency Virus, Type 1 Diabetes Mellitus and Peripheral Neuropathy: A Case Report.
}

\begin{abstract}
ABSTRACT

Background: Peripheral neuropathy (PN) may be idiopathic, iatrogenic, or be caused by any number of chronic diseases such as human immunodeficiency virus (HIV) and type 1 diabetes mellitus (DM1). PN is of particular interest to physical therapists, because it contributes to an individual's risk of falling. Purpose: (1) To describe a community-dwelling older adult with HIV, DM1, PN, and neurotoxic medication use (2) Highlight the pathophysiology of each diagnoses and resulting neuropathy and describe their effect on clinical decision-making when they are both present. Case Description: A seventy-two year-old man presented to outpatient physical therapy with PN and concurrent HIV and DM1. Physical examination identified decreased somatosensation and proprioception amongst other findings. Based on Functional Reach Test (FRT) and the Activities-Specific Balance Confidence Scale (ABC) fall risk cutoff scores, he was at risk of falling. Due to his PN, he was hindered in his ability to maintain balance in low-light situations, traverse stairs with objects in hand, and navigate crowded spaces while traveling and taking photographs. Intervention included balance-challenging neuromotor exercises, progressing in difficulty, and including static, dynamic, anticipatory, and reactive balance interventions. Outcomes: Despite chronic health conditions, the patient experienced meaningful improvements in balance ability and balance confidence. Over 5 sessions of physical therapy in 7 weeks, he improved his scores and was no longer a fall risk on the FRT and ABC. Discussion: PN may be the result of a single diagnosis, or multiple concurrent diagnoses. Studies are much more likely to include individuals with PN from a single source, as opposed to multiple concurrent diagnoses. In the presence of multiple etiologies, it is difficult to determine the best physical therapy intervention approach. Areas for future research may take two directions: (1) Including patients with coexisting conditions in trials (2) Stratification with very clear description of diagnoses in studies seeking optimal examination and intervention approaches. Conclusion: In the absence of clearer guidelines and stratification, an understanding of pathophysiology, patient goals and expectations, and preliminary published evidence should be used to develop an individualized approach to evaluating and treating individuals with PN.
\end{abstract}

\footnotetext{
Author Bio(s)

Kevin J. KohI PT, DPT is a licensed physical therapist in the State of Colorado, and is employed as a physical therapist at Sky Ridge Medical Center in Lone Tree, CO.
}

Tara Ferguson PT, DPT, COMT is a licensed physical therapist in the State of Colorado, and is employed as a physical therapist at St. Anthony's Hospital in Lakewood, CO.

Shane O'Malley PT, DPT, OCS is a licensed physical therapist in the State of Colorado.

Tamara S. Struessel PT, DPT, OCS, MTC is Assistant Professor in the Doctor of Physical Therapy Program at the University of Colorado, Anschutz Medical Campus. She is a licensed physical therapist in the State of Colorado. 


\title{
TIAHSP \\ The Internet Journal of Allied Health Sciences and Practice \\ Dedicated to allied health professional practice and education
}

Vol. 17 No. 3 ISSN 1540-580X

\section{A Community-dwelling Older Adult with Concurrent Human Immunodeficiency Virus, Type 1 Diabetes and Peripheral Neuropathy: A Physical Therapy Case Report}

\author{
Kevin Kohl1 \\ Tara Ferguson ${ }^{2}$ \\ Shane O'Malley \\ Tamara S. Struessel ${ }^{1}$
}

1. University of Colorado, Anschutz Medical Campus

2. St. Anthony's Hospital

\section{United States}

\begin{abstract}
Background: Peripheral neuropathy (PN) may be idiopathic, iatrogenic, or be caused by any number of chronic diseases such as human immunodeficiency virus (HIV) and type 1 diabetes mellitus (DM1). PN is of particular interest to physical therapists, because it contributes to an individual's risk of falling. Purpose: (1) To describe a community-dwelling older adult with HIV, DM1, PN, and neurotoxic medication use (2) To highlight the pathophysiology of each diagnoses and resulting neuropathy and describe their effect on clinical decision-making when they are both present. Case Description: A seventy-two year-old man presented to outpatient physical therapy with PN and concurrent HIV and DM1. Physical examination identified decreased somatosensation and proprioception amongst other findings. Based on Functional Reach Test (FRT) and the Activities-Specific Balance Confidence Scale $(A B C)$ fall risk cutoff scores, he was at risk of falling. Due to his PN, he was hindered in his ability to maintain balance in low-light situations, traverse stairs with objects in hand, and navigate crowded spaces while traveling and taking photographs. Intervention included balance-challenging neuromotor exercises, progressing in difficulty, and including static, dynamic, anticipatory, and reactive balance interventions. Outcomes: Despite chronic health conditions, the patient experienced meaningful improvements in balance ability and balance confidence. Over 5 sessions of physical therapy in 7 weeks, he improved his scores and was no longer a fall risk on the FRT and ABC. Discussion: PN may be the result of a single diagnosis, or multiple concurrent diagnoses. Studies are much more likely to include individuals with PN from a single source, as opposed to multiple concurrent diagnoses. In the presence of multiple etiologies, it is difficult to determine the best physical therapy intervention approach. Areas for future research may take two directions: (1) Including patients with coexisting conditions in trials (2) Stratification with very clear description of diagnoses in studies seeking optimal examination and intervention approaches. Conclusion: In the absence of clearer guidelines and stratification, an understanding of pathophysiology, patient goals and expectations, and preliminary published evidence should be used to develop an individualized approach to evaluating and treating individuals with PN.
\end{abstract}

Keywords: physical therapy, peripheral neuropathy, HIV, type 1 diabetes mellitus

(c) The Internet Journal of Allied Health Sciences and Practice, 2019 


\section{BACKGROUND AND PURPOSE}

The annual medical cost of falls resulting in hospitalization exceeds 3.1 billion dollars in the United States. ${ }^{1}$ Peripheral neuropathy (PN) is a contributing factor for fall risk, ${ }^{2}$ and neuropathy may impact motor, sensory and/or autonomic peripheral nerves. ${ }^{2}$ This diagnosis is characterized by damage to the nerve and related structures such as myelin surrounding the nerve, and may result in pain, muscle weakness, decreased proprioception, decreased somatosensation, reduced or absent ankle reflexes, reduced balance control, and higher risk for falling. ${ }^{2,3} \mathrm{PN}$-induced sensory deficits are typically permanent, but patients can compensate by "up-training" other systems. ${ }^{4-7}$ Many different medical conditions can cause PN. (Table 1)

Table 1: Summary from Streckmann based on review of exercise interventions for PN2

\begin{tabular}{|l|}
\multicolumn{1}{|c|}{ Source/Type of Peripheral Neuropathy } \\
\hline Alcohol Induced \\
\hline Amyloidosis \\
\hline Anti-myelin-associated glycoprotein \\
\hline Autoimmune \\
\hline Charcot-Marie-Tooth Disease \\
\hline Chemotherapy Induced \\
\hline Chronic inflammatory demyelinating polyradiculoneuropathy \\
\hline Chronic Acquired Peripheral Neuropathy \\
\hline Chronic Renal Disease \\
\hline Diabetic Peripheral Neuropathy (Type 1 DM) \\
\hline Diabetic Peripheral Neuropathy (Type 2 DM) \\
\hline Diphtheria \\
\hline Hereditary motor and sensory neuropathy (HMSN) \\
\hline HIV Induced \\
\hline Idiopathic Peripheral Neuropathy \\
\hline Infection induced \\
\hline Inflammatory peripheral neuropathy after Guillain-Barré Syndrome \\
\hline Liver Transplant familial amyloid polyneuropathy (FAP) \\
\hline Lyme Disease \\
\hline Medication Induced \\
\hline Metabolic imbalance induced neuropathy \\
\hline Nutritional deficiency induced neuropathy \\
\hline Sensory Neuron Disease \\
\hline Toxic Neuropathy \\
\hline
\end{tabular}

Human Immunodeficiency Virus (HIV) and Type 1 Diabetes Mellitus (DM1) are two chronic conditions that both cause peripheral neuropathies, but with differing mechanisms., ${ }^{3,8-12}$ Nationally, 1.1 million people are infected with HIV, and $57 \%$ of patients with HIV experience a peripheral neuropathy of some type due to medication side-effects and/or immunomodulatory mechanisms.3,8,9 Similarly, 1 million people are living with DM1, and $33 \%$ of these patients develop peripheral neuropathies due to microvascular disease. ${ }^{4,10}$ The pathophysiology of PN varies depending on the disease process or medication side effect. Alterations in DNA, protein restructuring, and neuronal dysfunction have all been implicated as potential contributors to PN. ${ }^{13-15}$ Despite varied causations, it is typically difficult to clinically distinguish relative contributions to PN in a patient with multiple risk factors. ${ }^{3,15}$

Individuals with both HIV and DM1 are prone to have balance deficits from neuropathy and potentially iatrogenic deficits linked to medications. Balance training improves balance ability in individuals with DM1-associated peripheral neuropathies.4,16 The research for patients with HIV-associated peripheral neuropathies largely focuses on pain control and balance rehabilitation. These patients demonstrated decreased center of mass sway during tandem stance and increased gait speed during dual motor-cognitive task following balance training. ${ }^{5}$

PN is well researched in individuals with isolated HIV or DM1, but information is scarce on the implications for PN when these conditions exist concurrently, and how training may, or may not be effective in improving balance and function when HIV and DM1 coexist. Purpose: (1) To describe a community-dwelling older adult with HIV, DM1, PN, and neurotoxic medication use (2) Highlight 
the pathophysiology of each diagnoses and resulting neuropathy and describe their effect on clinical decision-making when they are both present.

\section{CASE DESCRIPTION}

\section{Examination}

A seventy-two year-old man presented to outpatient physical therapy with the primary diagnosis of polyneuropathy associated with DM1 and HIV, and concurrent hypertension and hypercholesterolemia. The patient reported a 30-year history of HIV. Onset of DM1 was unknown. Given the expected juvenile onset, it was likely that both diseases had been concurrent and interacting for as long as 30 years. Physical therapy referral was for decreased balance ability during functional tasks, and he reported difficulty with maintaining balance while moving in low-light situations, ascending and descending stairs with objects in hand, and walking in crowds. He lived an active life after retiring as a health professional, including frequent travel, recreational photography, and participation in community theater. He sustained a non-injurious fall one month earlier while standing on ice and suddenly being pulled by his leashed dog. He noted primarily relying on his vision for balance and used eyeglasses for vision correction. He sought to improve his confidence in his abilities and reported improved balance after an episode of physical therapy intervention 10 years prior.

Table 2. Medications and clinical symptoms

\begin{tabular}{|c|c|c|}
\hline $\begin{array}{c}\text { Medication } \\
\text { (Generic/Brand) }\end{array}$ & Classification/Intended Treatment ${ }^{17}$ & Clinical Significance \\
\hline Aspirin & Antipyretic, non-opioid analgesic & $\begin{array}{l}\text { Increases risk for gastrointestinal bleeds and } \\
\text { anemia. }{ }^{17}\end{array}$ \\
\hline Clonazepam/Klonopin $\circledast$ & Anticonvulsant, benzodiazepine & $\begin{array}{l}\text { May cause ataxia or hypotonia, contributing to } \\
\text { balance disturbances. }{ }^{17}\end{array}$ \\
\hline Efavirenz*/Sustiva ${ }^{\circledR}$ & Antiretroviral & $\begin{array}{l}\text { Reverse transcriptase inhibitor for HIV-1. An } \\
\text { ART and therefore associated with PN. }{ }^{3}\end{array}$ \\
\hline Fenofibrate/Lipofen ${ }^{\circledR}$ & Lipid-lowering agent & May cause nausea, fatigue, and headaches. ${ }^{17}$ \\
\hline Fluticasone/Flovent HFA® & Steroidal anti-inflammatory & $\begin{array}{l}\text { Can lead to muscle wasting and osteoporosis } \\
\text { if taken regularly for extended periods of } \\
\text { time. } .^{17}\end{array}$ \\
\hline Furosemide/Lasix ${ }^{\circledR}$ & Diuretic & $\begin{array}{l}\text { May cause blurred vision, headaches, and } \\
\text { dizziness. }{ }^{17}\end{array}$ \\
\hline Hydrochlorothiazide/HCTZ® & Antihypertensive, diuretic & May cause headache and hyperglycemia. ${ }^{17}$ \\
\hline Insulin/Humulin® & Antidiabetic, hormone & $\begin{array}{l}\text { May cause hypoglycemia and rarely, diabetic } \\
\text { ketoacidosis. }{ }^{17}\end{array}$ \\
\hline Lisinopril/Zestril@ & Antihypertensive, ACE inhibitor & $\begin{array}{l}\text { May occasionally cause hypotension, } \\
\text { syncope, and dizziness. }{ }^{17}\end{array}$ \\
\hline Omeprazole/Prilosec $®$ & Proton-pump inhibitor & $\begin{array}{l}\text { May cause dizziness, headache, nausea, and } \\
\text { vomiting. }{ }^{17}\end{array}$ \\
\hline Quetiapine/Seroquel $\circledast$ & Antipsychotic, mood stabilizer & $\begin{array}{l}\text { May cause agitation, headache, dizziness, } \\
\text { hypotension, and abdominal pain. }{ }^{17}\end{array}$ \\
\hline Raltegravir*/lsentress $\circledast$ & Antiretroviral & $\begin{array}{l}\text { An HIV-1 replication inhibitor. An ART and } \\
\text { therefore associated with PN. }{ }^{3}\end{array}$ \\
\hline Zolpidem/Ambien ${ }^{\circledR}$ & Sedative & $\begin{array}{l}\text { May cause dizziness, headache, and } \\
\text { drowsiness. }{ }^{17}\end{array}$ \\
\hline
\end{tabular}

\footnotetext{
${ }^{*}$ Known to contribute to $\mathrm{PN}$ in some patients
}

Of his thirteen medications (Table 2), 2 were antiretroviral therapies (ARTs), which are associated with PN. ${ }^{3}$ Although the duration of ART use was unknown, it is likely that use of ARTs or other similarly neurotoxic medications spanned most of the 30 years since his HIV diagnosis.

\section{Physical Examination}

Based on his history of HIV, DM1, PN, and chronic ART use, it was hypothesized that the patient would present with decreased functional balance due to impairments in the musculoskeletal and neuromuscular systems. Following a systems review (see Table 3 ), the therapist performed tests and measures of the musculoskeletal and neuromuscular systems including balance, strength, sensation, proprioception, and vestibular function (see Table 4). Gait was steady without the use of an assistive device, although 
he occasionally grasped stationary objects as he turned corners. He did not rely on the objects for major balance correction. Because of his reported balance challenges, the Functional Reach Test (FRT) and The Activities-Specific Balance Confidence Scale (ABC) were chosen as outcome measures. The scores on both measures indicated risk for falls (See Table 5). ${ }^{18,19}$

Table 3: Systems review

\begin{tabular}{|c|l|l|}
\hline System & \multicolumn{1}{|c|}{ Findings } & \multicolumn{1}{c|}{ Decision \& Rationale } \\
\hline Cardiovascular/Pulmonary & $\begin{array}{l}\text { Respiration appropriate during rest, } \\
\text { exercise, and recovery. No } \\
\text { cardiovascular data obtained. }\end{array}$ & $\begin{array}{l}\text { Further examination not indicated for } \\
\text { pulmonary system. No cardiovascular } \\
\text { data was obtained. See Discussion. }\end{array}$ \\
\hline Musculoskeletal & Difficulty with balance tasks. & $\begin{array}{l}\text { Requires further examination and } \\
\text { potential intervention. }\end{array}$ \\
\hline Neuromuscular & Difficulty with balance tasks. & $\begin{array}{l}\text { Requires further examination and } \\
\text { potential intervention. }\end{array}$ \\
\hline Integumentary & $\begin{array}{l}\text { Skin appears intact. Patient reports } \\
\text { performing foot checks based on his } \\
\text { knowledge as a healthcare professional. }\end{array}$ & Further examination not indicated. \\
\hline Cognitive/ Communication & $\begin{array}{l}\text { Patient appropriately interacts with } \\
\text { therapist. }\end{array}$ & Further examination not indicated. \\
\hline Psycho-emotional & $\begin{array}{l}\text { Mood and responses appear } \\
\text { appropriate for given situation. }\end{array}$ & Further examination not indicated. \\
\hline
\end{tabular}

Table 4: Tests and measures

\begin{tabular}{|l|l|l|}
\hline \multicolumn{1}{|c|}{ Impairment } & \multicolumn{1}{c|}{ Test/Measure } & \multicolumn{1}{c|}{ Finding } \\
\hline Static Balance & FRT18 & 6 inches $(15.24 \mathrm{~cm})$ \\
\hline Balance Confidence & ABC 20 & $62 \%$ \\
\hline Proprioception & Passive Joint Position Sense ${ }^{21}$ & $\begin{array}{l}\text { Great toe and ankle impaired } \\
\text { bilaterally }\end{array}$ \\
\hline Sensation & Dermatome, Light Touch 22 & $\begin{array}{l}\text { Diminished in stocking } \\
\text { pattern bilaterally }\end{array}$ \\
\hline Gross Muscle Strength & Myotome Testing 23 & $\begin{array}{l}\text { No evidence of myotomal } \\
\text { weakness }\end{array}$ \\
\hline Vestibular Function & Vestibulo-Ocular Reflex24 & $\begin{array}{l}\text { No evidence of vestibular } \\
\text { dysfunction }\end{array}$ \\
\hline
\end{tabular}

\section{Outcome Measures}

FRT is an assessment of stability in static standing, with strong intrarater and interrater reliability for community-dwelling elderly (CDE). ${ }^{18,25} \mathrm{~A}$ cut-off score of $<7$ inches $\left(17.8 \mathrm{~cm}\right.$ ) is related to decreased mobility and activities of daily living (ADL). ${ }^{18}$ The FRT was prioritized due to its excellent correlation with walking speed $(r=0.71)$ and mobility skills $(r=0.65)$, and its moderate correlation with ADL performance $(r=0.48) .{ }^{18}$

The $A B C$ is a sixteen-question self-report survey that assesses confidence during daily situations that challenge balance. The $A B C$ was chosen because the patient had a goal of increasing confidence in his own ability to maintain balance. An ABC score of < $67 \%$ correlates with increased risk of falling in CDE. ${ }^{19}$ The ABC has excellent correlation with the Berg Balance Scale (BBS) $(r=$ $0.75)$ and the Timed Up \& Go Test (TUG) $(r=0.69) .{ }^{26}$ See Table 5 for additional psychometrics of the FRT and ABC. 
Table 5: Psychometrics of outcome measures

\begin{tabular}{|c|c|c|}
\hline Measure & FRT & ABC \\
\hline Intrarater Reliability & ICC $=0.8918$ & ICC $=0.94^{27^{*}}$ \\
\hline Interrater Reliability & $r=0.9725$ & $r=0.92^{28}$ \\
\hline $\begin{array}{c}\text { Minimal Detectable Change } \\
\text { (MDC) }\end{array}$ & 2.88 in. $(7.32 \mathrm{~cm})^{29 *}$ & $13 \% \%^{27^{*}}$ \\
\hline $\begin{array}{c}\text { Standard Error of Mean (SEM) } \\
\text { Fall Risk Cut-off }\end{array}$ & 1.03 in. $(2.64 \mathrm{~cm})^{29 *}$ & $1.197 \% \%^{30}$ \\
\hline Internal Consistency & $<7$ in. $(17.8 \mathrm{~cm})^{18}$ & $<67 \% 19$ \\
\hline
\end{tabular}

ICC = Intra-class correlation coefficient

*Established for patients with Parkinson's disease

\section{Evaluation}

The patient presented with PN secondary to concurrent HIV, DM1 and neurotoxic medication use, with findings of decreased distal lower extremity somatosensation and proprioception bilaterally. This pathologic process hindered his ability to perform tasks such as maintaining balance in low-light situations, traversing stairs with objects in hand, and navigating crowded spaces. These difficulties hindered him in his participations as a traveler and photographer (See Figure 1).
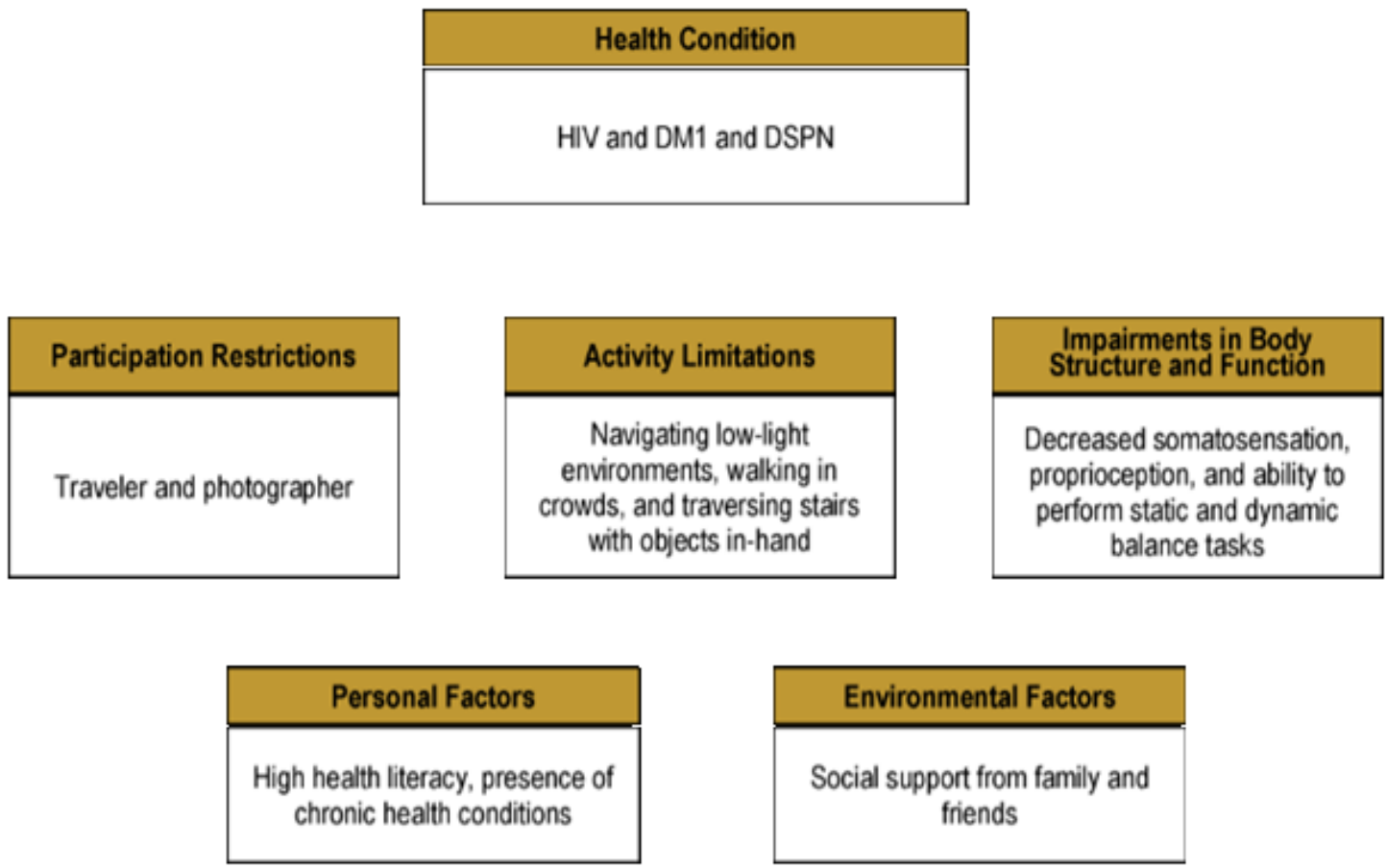

Figure 1: ICF model of patient's condition

\section{Prognosis}

Prognosis considered medical, environmental, and personal factors. Neuropathy and the associated activity limitations are expected to gradually worsen as a result of the progressive and chronic nature of his health conditions. ${ }^{3,8-12}$ Progression of PN was expected not only due to the disease processes of DM1 and HIV, but also as a side effect of ART medications. ${ }^{3,12}$ Additionally, CDE who take $\geq 4$ medications are at an increased risk for falls. ${ }^{31}$ He took thirteen medications at the time of evaluation and this 
number is not expected to decrease as he ages, compounding his fall risk. Therefore, his long-term medical prognosis for improvement in balance was poor.

Despite expected PN progression, exercise interventions have been shown to improve motor and sensory function, which translate to improved balance and gait. ${ }^{16}$ Based on existing cutoffs, he was at risk of falls on the FRT and ABC. ${ }^{18,19}$ In individuals with diabetic neuropathy, 8 weeks of balance training focused physical therapy is expected to lead to improvement in FRT and ABC scores. ${ }^{32}$ Balance intervention has also been associated with balance improvement in patients with HIV. ${ }^{5}$ Accordingly, his shortterm prognosis for improvement in balance function was good. However, the authors were unable to find information on balance improvement in the presence of concurrent diagnoses.

The patient's prognosis was positively affected by his health literacy and strong social support. Patients with adequate health literacy consistently demonstrate better adherence to prescribed interventions and have lesser HIV symptom intensity and body change distress. ${ }^{33,34}$ Adherence also correlates positively with social support. 33,35 Overall personal and environmental factors therefore indicate that improved functional outcomes were expected. ${ }^{33-35}$ Considering the negative and positive prognostic factors, a long-term progression in PN was expected, but with a short-term improvement in function with physical therapist management.

\section{Plan of Care and Goals}

The plan of care was created from the patient-identified activity and participation limitations in the ICF model. It included 8 weekly sessions of static and dynamic balance exercises to train anticipatory and reactive balance, with the goal of enhancing compensatory balance strategies. In addition, a 10-minute daily home exercise program (HEP) was planned to reinforce in-clinic balance exercises. Goals for the patient (Table 6) were set based on the challenges he identified considering both his personal objectives for physical therapy and expectation for clinical improvement.

Table 6: Goals for intervention

\begin{tabular}{|l|l|l|}
\hline \multicolumn{1}{|c|}{ Goal } & \multicolumn{1}{|c|}{ Timeframe } & \multicolumn{1}{c|}{ Rationale } \\
\hline $\begin{array}{l}\text { Patient will increase FRT } \\
\text { score by } \geq 2 \text { inches }\end{array}$ & 8 weeks & $\begin{array}{l}\text { Average improvement in FRT score is } 8 \% \\
\text { following balance training32 }\end{array}$ \\
\hline $\begin{array}{l}\text { Patient will increase ABC } \\
\text { score by } \geq 15 \%\end{array}$ & 8 weeks & $\begin{array}{l}\text { Average improvement in ABC score is } \\
13 \% \text { following compensatory balance } \\
\text { training32 }\end{array}$ \\
\hline
\end{tabular}

\section{Intervention}

Intervention primarily focused on balance-challenging neuromotor exercise (See Table 7). The combination of in-person intervention and a HEP met the guidelines for neuromotor exercise prescription per the American College of Sports Medicine. ${ }^{36}$ Progression of each exercise occurred as the patient mastered the given exercise, as no optimal strategy for progression of neuromotor exercise has been identified. ${ }^{36}$ The exercises began with a static balance focus including stance on ground, foam, and a rocker board, then were progressed to be more dynamic with variations such as challenging balance during walking, plyometric stepping, and hopping. Eyes-closed conditions for exercises were included due to his noted visual dominance and in order to "uptrain" vestibular and somatosensory systems. The patient's personal activity and participation goals were considered as exercise was progressed. Due to his scheduling preference, he attended 5 weekly sessions of physical therapy intervention over 7 weeks.

Table 7: Interventions

\begin{tabular}{|c|c|c|c|c|c|c|c|c|}
\hline \multirow{2}{*}{ Activity } & \multirow{2}{*}{ Frequency } & \multirow{2}{*}{ Intensity ${ }^{37}$} & \multirow{2}{*}{ Duration } & \multicolumn{5}{|c|}{ Visit Number } \\
\hline & & & & 1 & 2 & 3 & 4 & 5 \\
\hline Recumbent Biking warm up & In Clinic & 3 METs & 5 min. & $\mathrm{X}$ & $X$ & $X$ & $X$ & $\mathrm{X}$ \\
\hline Grapevine / Braiding 32 & Daily (HEP) & 3 METs & $1 \mathrm{~min}$. & $\mathrm{X}$ & $\mathrm{X}$ & $\mathrm{X}$ & $\mathrm{X}$ & $\mathrm{X}$ \\
\hline Tandem Walking ${ }^{32}$ & Daily (HEP) & 3 METs & $1 \mathrm{~min}$. & $\mathrm{X}$ & $\mathrm{X}$ & $\mathrm{X}$ & $\mathrm{X}$ & $X$ \\
\hline Standing on Foam ${ }^{32}$ & Daily (HEP) & 2 METs & $1 \mathrm{~min}$. & $\mathrm{X}$ & $X$ & $X$ & $X$ & $X$ \\
\hline Rocker Board 4 & In Clinic & 2 METs & 5 min. & & $\mathrm{X}$ & & & \\
\hline Single Limb Stance (Eyes Open) ${ }^{32}$ & In Clinic & 3 METs & $1 \mathrm{~min}$. & & & $\mathrm{X}$ & & \\
\hline Single Limb Stance (Eyes Closed) ${ }^{32}$ & In Clinic & 3 METs & $1 \mathrm{~min}$. & & & $\mathrm{X}$ & & \\
\hline Walking on Uneven Surface (Reactive) 32 & In Clinic & 3 METs & $1 \mathrm{~min}$. & & & & $\mathrm{X}$ & \\
\hline
\end{tabular}




\begin{tabular}{|c|c|c|c|c|c|}
\hline Side-stepping & In Clinic & 3 METs & $1 \mathrm{~min}$. & $\mathrm{X}$ & \\
\hline Grapevine / Braiding & In Clinic & 3 METs & $1 \mathrm{~min}$. & $X$ & \\
\hline Rocker Board with arms occupied ${ }^{4}$ & In Clinic & 2 METs & $5 \mathrm{~min}$. & $\mathrm{X}$ & \\
\hline Single-knee on Edge of Bed Balance & In Clinic & 2 METs & $20 \mathrm{sec}$. & $x$ & $\mathrm{X}$ \\
\hline $\begin{array}{l}\text { Balance recovery following supported } \\
\text { leaning } 38\end{array}$ & In Clinic & 2 METs & $1 \mathrm{~min}$. & & $\mathrm{x}$ \\
\hline Quick stepping plyometrics 2" step 32 & In Clinic & 4 METs & $1 \mathrm{~min}$. & & $\mathrm{X}$ \\
\hline Walking with quick reactive turns 32 & In Clinic & 4 METs & $2 \min$. & & $\mathrm{X}$ \\
\hline Walking with head turns ${ }^{32}$ & In Clinic & 3 METs & $2 \min$. & & $\mathrm{X}$ \\
\hline Two foot hopping 32 & In Clinic & 3 METs & $2 \min$. & & $\mathrm{X}$ \\
\hline
\end{tabular}

$\mathrm{MET}=$ Metabolic Equivalent of Task HEP=Home Exercise Program

\section{OUTCOMES}

Outcome measures were completed upon evaluation and on the final visit. A summary of the outcomes can be found in Table 8 and in Figure 2. The patient met all stated goals in 7 weeks and he was no longer at risk for falls per the FRT and ABC, although he was still 1 inch below age group norms on the FRT. ${ }^{39}$ Scores below the 7 inch cutoff of FRT identify patients who have difficulty leaving the neighborhood on their own, who are limited in mobility skills, and who are most restricted in ADLs. ${ }^{18}$ Scores on the ABC below the $67 \%$ cutoff accurately identify people who fall $84 \%$ of the time. ${ }^{19}$

Scores on the ABC and FRT exceeded the published MDC's for each measure. ${ }^{27,29}$ The outcomes are meaningful in light of the patient's goals, as they reflect an improvement in performance and confidence with balance related activities. For the patient, this meant pursuing traveling and photography without increased fear of falling.

Table 8: Outcomes

\begin{tabular}{|c|c|c|c|c|c|}
\hline Measure & Week 1 & Week 7 & Fall Risk Cutoff & MDC & Mean Score \\
\hline FRT & 6 inches & 12 inches & $<7$ inches $^{18}$ & 2.88 inches $^{29^{*}}$ & 13.16 inches $^{39 * *}$ \\
\hline ABC & $62 \%$ & $77 \%$ & $<67 \% \%^{19}$ & $13 \%^{27^{*}}$ & Unknown \\
\hline
\end{tabular}

${ }^{*}$ For patients with Parkinson's disease

${ }^{* *} \mathrm{CDE}$ males, $70-87$, no recent falls or major neurological or orthopedic diagnoses

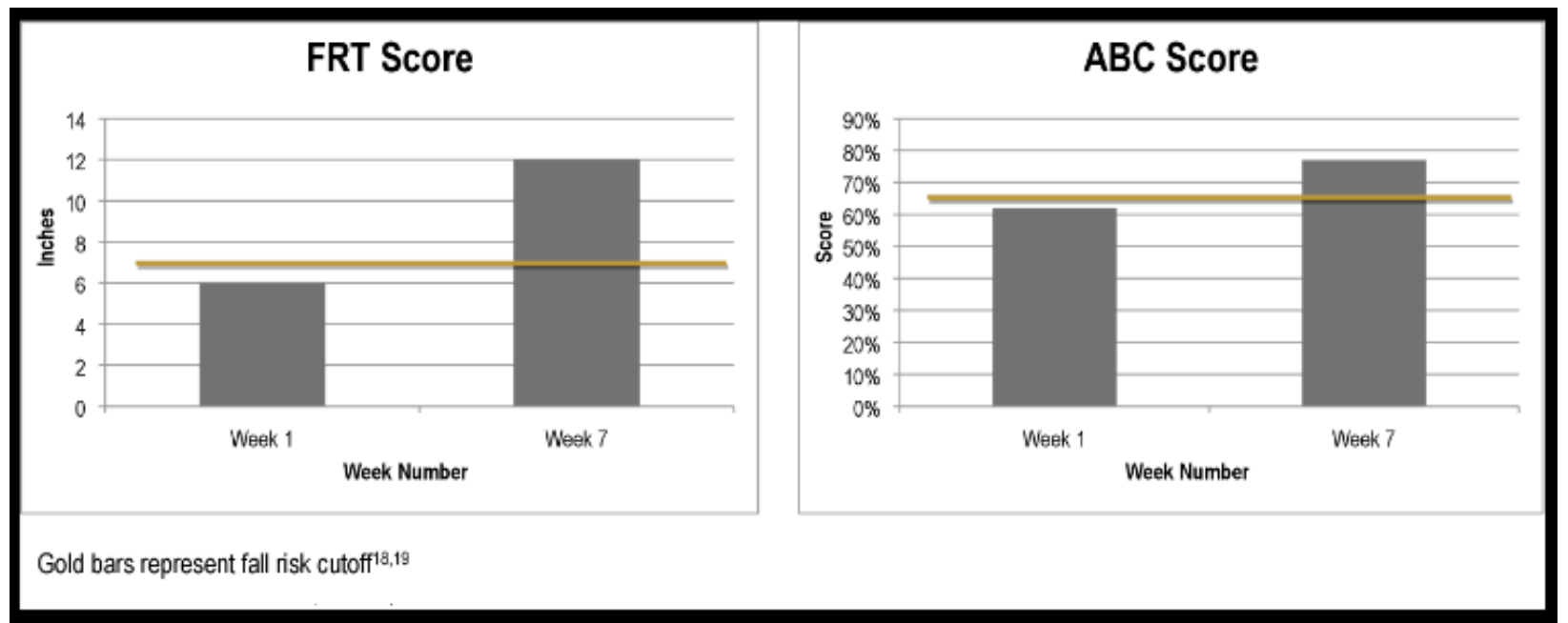

Figure 2: FRT and ABC outcomes

\section{DISCUSSION}

This case report described the physical therapist management of a community-dwelling older adult with HIV, DM1, PN, and neurotoxic medication use, with a focus on pathophysiology and its effect on clinical decision-making. Improvement in balance was meaningful to the patient, and the outcome measures related to both patient goals of improving confidence and functional balance ability. Confidence in his ability to participate in travel and photography improved over the course of physical therapy treatment. 
The relative contribution of ART medication, the HIV disease process, and the DM1 disease process on the patient's neuropathy is unknown. Most likely, his PN was the product of multiple pathophysiologic processes that adversely impacted his peripheral nerves over time. ART use may lead to mitochondrial DNA damage in axons of peripheral nerves. ${ }^{13}$ Neurotoxicity may also occur secondary to the viral infection of HIV itself - infected macrophages are known to release inflammatory cytokines that may cause nerve fiber damage. ${ }^{14}$ Glycosylated proteins, as a result of DM1, also contribute to nerve dysfunction. ${ }^{15}$

Current research supports physical therapist management and balance interventions for patients with either HIV, DM1, or PN.4,5,16 However; the current literature lacks intervention guidance when HIV, DM1, and PN coexist. Notable outcomes in previous studies that isolate either HIV or DM1 include decreased postural sway, increased balance confidence, increased gait speed, decreased pain (if present), and overall reduced fall risk with balance interventions. 4,5,7,16 A review by Streckmann et al indicates that differing intervention may be appropriate depending on the source of the neuropathy, "metabolically induced" like with Diabetes Mellitus or "non-metabolically induced." 2 Based on their review, they suggested balance intervention for metabolically induced PN focus on endurance exercises as a way of reducing body weight, and inducing glycemic control amongst other mechanisms. For PN with a non-metabolic etiology, they suggest sensorimotor/balance intervention to induce neural adaptation, taking advantage of the nervous system's plasticity. They specifically suggest that exercises focused on sensorimotor training be limited to 5 , and that they be performed for twenty to forty seconds to allow recovery, and to minimize "neural fatigue." ${ }^{2}$ However, these studies lack guidance and information on physical therapist management of an individual with multiple concurrent health conditions. In an individual such as the patient in this case, a blend of these two approaches would have been most appropriate. Shorter duration sensorimotor balance interventions with longer breaks may have allowed more complete inter and intra-session recovery. That said, the reduced rest may have been more effective at creating an endurance component, which is recommended in those with DM. ${ }^{2}$

The patient's score on the FRT increased by 6 inches in 7 weeks. While this may wholly reflect a balance improvement, alternative explanations must be considered. The evaluating therapist gave the patient one trial to complete the FRT each time that it was performed. The correct clinical administration of the FRT calls for performing 5 trials and recording the average of the final 3 trials. ${ }^{18}$ The performance of only one trial may have led the patient to complete the FRT cautiously and below his true functional level. In addition, the follow-up measurement could reflect familiarity with the test and confidence in balance ability following treatment, thus providing an inaccurate disparity between the two scores. Despite this possibility, a 100\% increase in score is likely meaningful.

In light of the patient's goals, intervention focused on static and dynamic balance activities. The interventions performed were driven by patient input, research findings, and therapist experience, the 3 tenets of Evidence Based Practice; however, more targeted and potentially appropriate interventions may have been chosen had a more thorough initial balance evaluation been used. ${ }^{40}$ One suggested measure is the Balance Evaluation Systems Test (BESTest). ${ }^{38}$ The BESTest provides information on specific deficits across the balance systems of biomechanical restraints, stability limits, anticipatory postural adjustments, postural responses, sensory orientation, and stability in gait. ${ }^{38}$ Besides intervention guidance, this measure has excellent correlation with the ABC $(r=0.636) .{ }^{38}$ Intervention could have been structured to specifically address deficits identified by the BESTest.

Several examination items would have provided a more complete picture of the patient prior to intervention. Achilles' tendon deep tendon reflex (DTR) may have provided information regarding the severity of PN. ${ }^{16}$ As a standard neurological examination tool, DTR testing should be performed with similar patients. ${ }^{16}$ In future management of similar patients, DTR's should be included. The physical therapist did not obtain blood glucose readings or cardiovascular vital signs from the patient during the episode of care. Obtaining these values would have improved patient safety, given the risks of exercising with DM1 and the cardiovascular risk profile of hypertension and hypercholesterolemia. ${ }^{16}$

Despite potentially different etiological processes causing PN, the impairments are thought to be similar across patients. ${ }^{7}$ However, it is currently unclear if the source of PN influences prognosis, progression, and response to physical therapy intervention. This case report serves as a foundation for identifying current gaps in the literature in complex individuals with PN. Areas for future research may take two directions: (1) Including patients with coexisting conditions in trials (2) Stratification with very clear description of diagnoses in studies seeking optimal examination and intervention approaches.

\section{CONCLUSION}

Physical therapists should have an awareness of differing pathophysiological processes in individuals with PN. This case report describes an individual with PN due to a combination of concurrent HIV, DM1, and neurotoxic medication use. The relative contribution of pathophysiologic and iatrogenic processes was unknown, and results in a complicated clinical presentation. Current research lacks guidance for physical therapist management of patients with multiple health conditions that contribute to PN. In the

( The Internet Journal of Allied Health Sciences and Practice, 2019 
absence of clearer guidelines and stratification, an understanding of pathophysiology, patient goals and expectations, and preliminary published evidence should be used to develop an individualized approach to evaluating and treating these individuals.

\section{REFERENCES}

1. Towne SD Jr, Ory MG, Smith ML. Cost of fall-related hospitalizations among older adults: environmental comparisons from the 2011 Texas hospital inpatient discharge data. Popul Health Manag. Dec 2014;17(6):351-6. [PMID: 25075812]

2. Streckmann F, Zopf EM, Lehmann HC, May K, Rizza J, et al. Exercise intervention studies in patients with peripheral neuropathy: a systematic review. Sports Med. Sep 2014;44(9):1289-304. [PMID: 24927670]

3. Stavros K, Simpson DM. Understanding the etiology and management of HIV-associated peripheral neuropathy. Current HIVIAIDS Reports. 2014;11(3):195-201. [PMID: 24969360]

4. Akbari M, Jafari H, Moshashaee A, Forugh B. Do diabetic neuropathy patients benefit from balance training? The Journal Of Rehabilitation Research And Development. 2012;49(2):333-8. [PMID: 27119372]

5. Veeravelli S, Najafi B, Marin I, Blumenkron F, Smith S, Klotz SA. Exergaming in older people living with HIV improves balance, mobility and ameliorates some aspects of frailty. J Vis Exp. Oct 6 2016(116):e54275-e54275. [PMID: 27768079]

6. Schenkman ML, Bowman JP, Gisbert RL, Butler RB. Clinical Neuroscience For Rehabilitation: Pearson Education; 2012.

7. Tofthagen C, Visovsky C, Berry DL. Strength and balance training for adults with peripheral neuropathy and high risk of fall: current evidence and implications for future research. Oncol Nurs Forum. 2012;39(5):E416-424. [PMID: 22940521]

8. Panneer N, Lontok E, Branson BM, Teo CG, Dan C, et al. HIV and Hepatitis C virus infection in the United States: Whom and how to test. Clin Infect Dis. 2014;59(6):875-82. [PMID: 24867787]

9. Gabbai AA, Castelo A, Oliveira ASB. HIV peripheral neuropathy. Handb Clin Neurol. 2013;115:515-29. [PMID: 23931799]

10. Menke A, Orchard TJ, Imperatore G, Bullard KM, Mayer-Davis E, Cowie CC. The prevalence of Type 1 Diabetes in the United States. Epidemiology. 2013;24(5):773-4. [PMID: 23903880]

11. Farsani SF, Souverein PC, Vorst MMJvd, Knibbe CAJ, Boer AD, Mantel-Teeuwisse AK. Chronic comorbidities in children with type 1 diabetes: a population-based cohort study. Arch Dis Child. 2015;100(8):763-768. [PMID: 25877155]

12. Ziegler D, Behler M, Schroers-Teuber M, Roden M. Near-normoglycaemia and development of neuropathy: a 24-year prospective study from diagnosis of type 1 diabetes. BMJ Open. 2015;5(6):e006559. [PMID: 26109108]

13. Lehmann HC, Chen W, Borzan J, Mankowski JL, Höke A. Mitochondrial dysfunction in distal axons contributes to human immunodeficiency virus sensory neuropathy. Ann Neurol. 2011;69(1):100-110. [PMID: 21280080]

14. Hao S. The molecular and pharmacological mechanisms of HIV-related neuropathic pain. Curr Neuropharmacol. 2013;11(5):499-512. [PMID: 24403874]

15. Duran-Jimenez B, Dobler D, Moffatt S, Rabbani N, Streuli CH, et al. Advanced glycation end products in extracellular matrix proteins contribute to the failure of sensory nerve regeneration in diabetes. Diabetes. 2009;58(12):2893-2903. [PMID: 19720799]

16. Kluding PM, Bareiss SK, Hastings M, Marcus RL, Sinacore DR, Mueller MJ. Physical training and activity in people with diabetic peripheral neuropathy: paradigm shift. Phys Ther. 2017;97(1):31-43. [PMID: 27445060]

17. $\quad$ Ciccone CD. Davis's Drug Guide For Rehabilitation Professionals. Philadelphia: F.A. Davis; 2013.

18. Weiner DK, Duncan PW, Chandler J, Studenski SA. Functional Reach: A marker of physical frailty. J Am Geriatr Soc. 1992;40(3):203-207. [PMID: 1538035]

19. Lajoie Y, Gallagher SP. Predicting falls within the elderly community: comparison of postural sway, reaction time, the Berg balance scale and the Activities-specific Balance Confidence (ABC) scale for comparing fallers and non-fallers. Arch Gerontol Geriatr. 2004;38(1):11-26. [PMID: 14599700]

20. Huang T-T, Wang W-S. Comparison of three established measures of fear of falling in community-dwelling older adults: Psychometric testing. Int J Nurs Stud. 2009;46(10):1313-1319. [PMID: 19394017]

21. Clark NC, Röijezon U, Treleaven J. Proprioception in musculoskeletal rehabilitation. Part 2: Clinical assessment and intervention. Manual Therapy. 2015;20(3):378-387. [PMID: 25787919]

22. Weise MD, Garfin SR, Gelberman RH, Katz MM, Thorne RP. Lower-extremity sensibility testing in patients with herniated lumbar intervertebral discs. The Journal Of Bone And Joint Surgery. American Volume. 1985/10/ 1985;67(8):1219-1224.

23. Kendall F. Muscles: Testing And Function With Posture And Pain, 5e. Baltimore, MD: Lippincott Williams \& Wilkins; 2005. 
24. Colagiorgio P, Colnaghi S, Versino M, Ramat S. A new tool for investigating the functional testing of the VOR. Front Neurol. 2013;4:165. [PMID: 24298265]

25. Franzen H, Hunter H, Landreth C, Beling J, Greenberg M, Canfield J. Comparison of functional reach in fallers and nonfallers in an independent retirement community. Phys Occupational Therapy In Geriatrics. 1999;15(4):33-40.

26. Hatch J, Gill-Body KM, Portney LG. Determinants of balance confidence in community-dwelling elderly people. Phys Ther. 2003;83(12):1072-9.

27. Steffen T, Seney M. Test-retest reliability and minimal detectable change on balance and ambulation tests, the 36-Item Short-Form Health Survey, and the Unified Parkinson Disease Rating Scale in People with Parkinsonism. Phys Ther. 2008;88(6):733-46.

28. Powell LE, Myers AM. The Activities-specific Balance Confidence (ABC) Scale. The Journals Of Gerontology. Series A, Biological Sciences And Medical Sciences. 1995;50A(1):M28-34.

29. Schenkman M, Cutson TM, Kuchibhatla M, Chandler J, Pieper C. Reliability of impairment and physical performance measures for persons with Parkinson's disease. Phys Ther. 1997;77(1):19-27. [PMID: 8996460]

30. Nemmers TMPT, Miller JW. Factors influencing balance in healthy community-dwelling women age 60 and older. Journal of Geriatric Physical Therapy. 2008;31(3):93-100. [PMID: 19856614]

31. Buatois S, Perret-Guillaume C, Gueguen R, Miget P, Vançon G, et al. A simple clinical scale to stratify risk of recurrent falls in community-dwelling adults aged 65 years and older. Physical Therapy. 2010;90(4):550-60. [PMID: 20203094]

32. Allet L, Armand S, de Bie RA, Golay A, Monnin D, et al. The gait and balance of patients with diabetes can be improved: a randomised controlled trial. Diabetologia. 2010;53(3):458-466. [PMID: 19921145]

33. Berkman ND, Sheridan SL, Donahue KE, Halpern DJ, Crotty K. Results: Relationship Of Health Literacy To Outcomes And Disparities: Agency for Healthcare Research and Quality (US); 2011.

34. Nokes KM, Coleman CL, Cashen M, Dole P, Sefcik E, et al. Health literacy and health outcomes in HIV seropositive persons. Res Nurs. Health. 2007;30(6):620-7. [PMID: 18022832]

35. Sherbourne CD, Hays RD, Ordway L, DiMatteo MR, Kravitz RL. Antecedents of adherence to medical recommendations: results from the Medical Outcomes Study. J Behav Med. 1992;15(5):447-68. [PMID: 1447757]

36. Garber CE, Blissmer B, Deschenes MR, Franklin BA, Lamonte MJ, et al. Quantity and quality of exercise for developing and maintaining cardiorespiratory, musculoskeletal, and neuromotor fitness in apparently healthy adults: Guidance for prescribing exercise. American College of Sports Medicine Position Stand. Med Sci Sports Exerc. 2011;43(7):1334-59. [PMID: 21694556]

37. Ainsworth BE, Haskell WL, Herrmann SD, Meckes N, Bassett DR Jr, et al. 2011 Compendium of Physical Activities: A second update of codes and MET values. Med Sci Sports Exerc. 2011;43(8):1575-81. [PMID: 21681120]

38. Horak FB, Wrisley DM, Frank J. The Balance Evaluation Systems Test (BESTest) to differentiate balance deficits. Phys Ther. 2009;89(5):484-98. [PMID: 19329772]

39. Duncan PW, Weiner DK, Chandler J, Studenski S. Functional reach: a new clinical measure of balance. J Gerontol. 1990;45(6):M192-7. [PMID: 2229941]

40. Sackett DL, Rosenberg WM, Gray JA, Haynes RB, Richardson WS. Evidence based medicine: what it is and what it isn't. BMJ (Clinical research ed). 1996;312(7023):71-2. [PMID: 17340682] 